\title{
Understanding the roles of fuels, climate and people in predicting fire: taking the long view
}

\author{
Robert D. Field ${ }^{1}, 2$, K. Fernandes ${ }^{3}$, K.C. Glover ${ }^{4}$, W.D. Hansen ${ }^{5}$, J. Rabinowicz ${ }^{6}$ and A.P. Williams ${ }^{7}$ \\ New York, USA, 23-25 October 2017
}

\begin{abstract}
The Conference on Fire Prediction Across Scales was held at Columbia University in New York, drawing over 120 attendees from academia, government and the private sector. Input from fire managers enhanced awareness among the fire modeling and paleo communities of the realworld importance of better understanding the drivers of changes in fire activity for safety and land management. The meeting was unique in connecting researchers studying fire prediction at all scales, from the behavior of a flame, to a single wildfire, to changes in global fire patterns from year to year. And, necessarily, to changes in fire over centuries and millennia. The paleofire aspects of the meeting covered advances made in obtaining, synthesizing and interpreting charcoal records from lake sediment and burn scars in tree rings.
\end{abstract}

David Bowman (U. Tasmania, Australia) described the recent fire-driven loss of Athrotaxis in Tasmania after a dry spring. In trying to understand the degree to which anthropogenic climate change was a factor, Bowman noted that Tasmania's highly variable fire climate makes climate-change attribution particularly challenging. The paleoecological record provides considerable insight, however, indicating strong El Niño-driven Athrotaxis losses during the late Holocene, serving as a long-term analogue for interpreting current fire regime changes. In New Zealand, Jed Kaplan (U. Oxford, UK) described simulations of vegetation cover over the past thousand years, suggesting Maori arrival as a likely explanation for fire-driven forest loss evidenced in charcoal and pollen records. Further work is needed to consider the climatic influence, given that the Maori arrival was preceded by a possibly confounding Medieval Warm period signal over New Zealand.

In the southwestern US, Rachel Loehman (USGS, USA) examined impacts of human activity on fire regimes over 1200-1900 CE in the Jemez region of New Mexico. Using process-based modeling, Loehman explained how high population densities, intensive agriculture, and fuelwood harvesting could contribute to a 25 -fold increase in fire activity, but offset by smaller individual fires on a more fragmented, shrub-dominated landscape. Katherine Glover provided the longest time-scale perspective of the conference, presenting charcoal and pollen data from the San Bernardino Mountains in southern California over 120,000 years from two lake cores. These data are unique in their potential to understand interactions between climate, fire and vegetation cover before the arrival of people.

Jennifer Marlon (Yale U., USA) provided a global perspective, updating on recent activity from the PAGES Global Paleofire Working Group, including the latest ( $\mathrm{v} 4$ ) Global Charcoal Database (Fig. 1). Marlon emphasized that, globally, there are pronounced relationships between climate and fire, which can be decoupled by human intervention. Over the western US for example, a 100-year history of aggressive fire suppression has led to a decrease

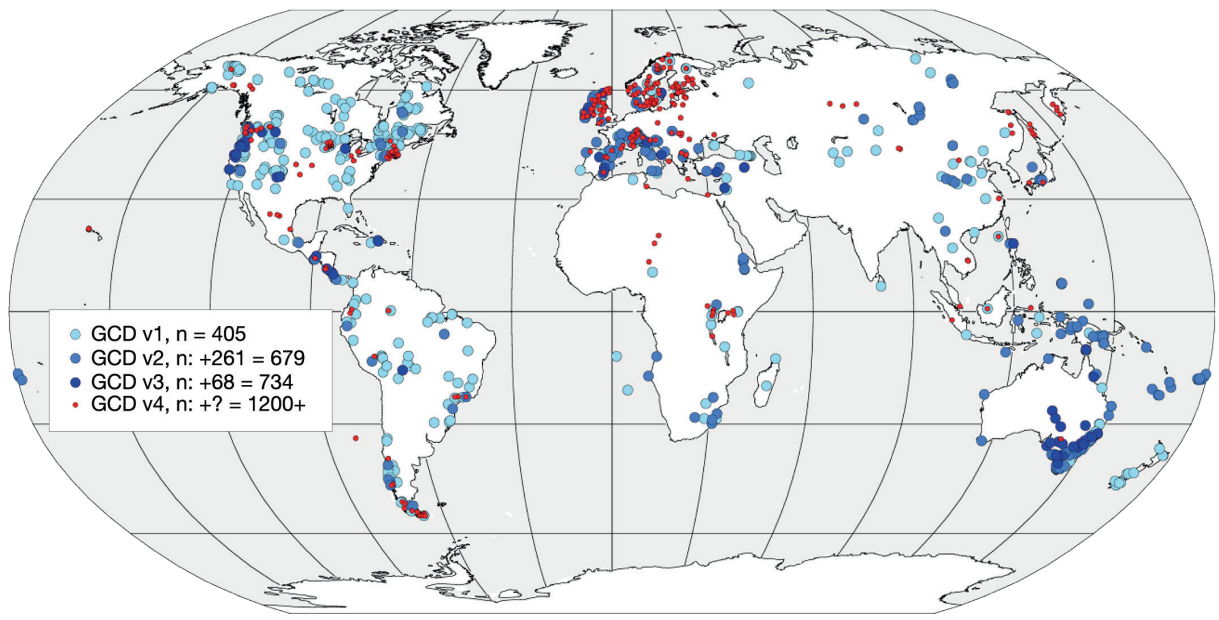

\section{AFFILIATIONS}

'Department of Applied Physics and Applied Mathematics, Columbia University, New York, USA ${ }^{2}$ NASA Goddard Institute for Space Studies, New York, USA

${ }^{3}$ International Research Institute for Climate and Society, Columbia University, New York, USA ${ }^{4}$ Climate Change Institute, University of Maine, Orono, USA

${ }^{5}$ Department of Integrative Biology, University of Wisconsin-Madison, USA

${ }^{6}$ Earth Institute, Columbia University, New York, USA 'Lamont-Doherty Earth Observatory, Columbia University, New York, USA

\section{CONTACT}

Robert D. Field: robert.field@columbia.edu

Figure 1: Distribution of charcoal records for successive versions of the Global Charcoal Database (courtesy of Patrick Bartlein and Jennifer Marlon). Data are available from the PAGES Global Paleofire Working Group at www. paleofire.org. 